\title{
Comparing Ethical Decision-making among Undergraduates: The Impact of Institutional Values
}

\author{
Gail F. Latta \\ Xavier University \\ Molly Dugan \\ Xavier University
}

This mixed-methods study explores the influence of institutional values on undergraduates' ethical decision making. Analysis focused on whether graduating seniors differed from incoming first-year students with respect to: a) the ethical principles, and b) institutional values reflected in their responses to six ethical dilemmas college students typically encounter. Both narrative and survey data were collected. Significant within-group effects revealed both first-year and senior students vary their decisionmaking strategies when responding to different ethical scenarios. Selective between-group differences were also observed, reflecting the influence of institutional values on students' ethical decision-making. Implications for student affairs professionals in higher education are discussed.

\section{INTRODUCTION}

The ethical development of undergraduate students is a focus of student affairs professionals in many colleges and universities, reflecting values embedded in institutional missions (King \& Mayhew, 2002). Universities strive to send graduates out into the world as well-rounded, ethical citizens. King and Mayhew (2002) articulate three reasons for studying the development of moral judgment among college students: 1) students typically enroll in college during times of transition in their lives that have moral implications; 2) academic institutions commonly identify the moral development of students as an objective in their mission statements, either implicitly or explicitly; and 3) college graduates generally assume leadership roles in society, requiring them to make decisions that impact the lives of others.

Research supports the expectation that students will develop morally and ethically in college. Jones and Watt (1999) reported a correlation between class standing and moral orientation, while Wilson, Rest, Blodizar, and Deemer (1992) found educational attainment was a direct predictor of adult moral judgment. Mayhew, Seifert, and Pascarella (2012) reported students in transitional phases of moral development are more likely to be influenced by college attendance. Mayhew \& King (2008) found the greatest impact on moral development stemmed from courses deemed "morally explicit" and pedagogical strategies that create a safe, supportive learning environment. Astin (1984) indicates extracurricular activities promote student development. However, despite evidence college students exhibit general changes in moral development, research on the content of students' ethical decision-making is limited. 
The formative impact of college attendance on many aspects of student development has been well established (Astin, 1984; King \& Mayhew, 2002), yet few studies have focused on the content of students' ethical decisions and their decision-making processes. Previous studies have focused more on what students believe to be ethical rather than how ethical decisions are made (see Mayhew et al., 2016 for a review). The limited research reporting developmental changes in ethical decision-making among college students has focused narrowly on business school graduates, and has not examined the influence of institutional values (Alghalith, 2018; Almasri \& Tahat, 2019; King \& Mayhew, 2002; Salimi, Kornelus, \& Abo-Hebeish, 2016). Research on ethical decision-making among business school majors cannot be considered representative of the general undergraduate population, because schools of business and management typically require a course in ethics (Craft, 2013). Thus there is need to expand study of the impact of college attendance on ethical decision-making to encompass all undergraduate students, specifically with respect to the influence of institutional values.

\section{RESEARCH QUESTIONS}

This case study compares the ethical decision-making philosophies of first-year and senior undergraduate college students, and the degree to which institutional values embedded in the mission of the university are reflected in the rationales reported by these respective student populations. Data were collected from a random sample of graduating seniors in April 2018, and from incoming first-year students in June 2018. Students were asked to respond to six ethical scenarios, providing both narrative and Likert-survey responses explaining: a) what actions they would take, and b) their rationale for doing so. Both the ethical decisions and rationales were analyzed to identifying the ethical principles and institutional values underlying participants' decisions. Four research questions (RQs) were addressed:

RQ1: Is there variation in the ethical principles incoming first-year students and graduating seniors employ in their ethical decision-making?

RQ2: To what extent are the values embedded in an academic institution's mission reflected in the ethical decision-making of first-year and senior students?

RQ3: Do the rationales reported for the ethical decisions made by incoming first-year and senior undergraduate students differ with respect to ethical principles and institutional values?

RQ4: Do the rationales of first-year and senior students who employ the same ethical principles in their decision-making integrate institutional values to differing degrees?

\section{THEORETICAL FRAMEWORK}

This study analyzed undergraduate students' ethical decision-making at a mid-sized, private, comprehensive institution of higher education, for evidence of six philosophical principles and six institutional values. Six ethical principles were examined: Kant's categorical imperative, utilitarianism, justice as fairness, altruism, pragmatism, and virtue ethics. Patterns of ethical decision-making among first-year and senior students were further examined for evidence of six institutional values: reflection, discernment, solidarity and kinship, service rooted in justice and love, Cura Personalis, and Magis.

\section{Ethical Decision-making Principles}

Ethical decision-making is a process by which individuals resolve ethical dilemmas, involving a combination of reasoning, conceptions of right and wrong, and consideration of alternative behavioral responses (Oliver and Hioco, 2012). Heyler, Armenakis, Walker, and Collier (2016) define ethical decision-making as "the process of recognizing a need, considering alternatives, identifying a morally acceptable option (i.e. what is considered right in a given culture) and implementing it" (p. 788). The 
process of ethical decision-making encompasses "all the stages an individual has to go through from the moment a moral problem arises until he or she engages in a given behavior" (Morales-Sánchez \& Cabello-Medina (2013, p. 718). While the process of ethical decision-making may be individualized, the outcomes of these decisions can be categorized as conforming to a finite set of philosophical perspectives (Rosen, 1978). The ethical principles underlying six of these philosophical perspectives form the conceptual framework for this study. These six ethical principles were selected because they represent distinct approaches to ethical decision-making scholars have identified to be commonly employed by the general population (Johnson, 2018).

The following conceptual definitions operationalized the six ethical principles used to code the ethical decision-making rationales elicited from participants in this study:

\section{Utilitarianism}

The utilitarian approach to ethical decision-making attempts to do the greatest good for the greatest number of people, taking into consideration the potential impact on others (Dion, 2012). Uutilitarianism encourages people to do what will bring about the most happiness for the most people (Graham, 2004).

\section{Categorical Imperative}

The categorical imperative is the essence of Kant's deontological approach, which asserts people have an obligation to do what is morally right in every circumstance, without regard for the consequences (Johnson, 2018). Deontology asserts people have a duty to base ethical decisions on immutable principles, making ethical decisions out of obedience to an objective, superordinate moral code (Johnson, 2018; Dion, 2012). The categorical imperative dictates ethical decisions must transcend wants and desires, compelling individuals to do what is right regardless the circumstance, because what is right for one must be right for all (Graham, 2004; von Platz, 2016).

\section{Justice as Fairness}

Rawls' theory of justice states that in order to act justly, and thus morally, equal rights and opportunities for all must take precedence (Rawls, 1999). Rawls $(1999,2001)$ asserts societal well-being dictates the sacrifices of some cannot justify the advantages of others, particularly with respect to the marginalized or less-advantaged.

\section{Pragmatism}

The pragmatism approach requires using moral imagination to consider possible alternative actions and potential impacts on others in making ethical decision-making (Fesmire, 2013). Pragmatism allows flexibility in approaching ethical dilemmas, and encourages decision makers to revise their actions to reflect a holistic consideration of the situation (Johnson, 2018).

\section{Altrusim}

An altruistic approach to ethical decision-making focuses on loving one's neighbor and doing what benefits others without concern for self (Kraut, 2016). Altruism requires doing good for others or preventing them from experiencing harm (Johnson, 2018).

\section{Virtue Ethics}

A virtue ethics approach to ethical decision-making asserts people are made good through their actions, so individuals' actions should be virtuous, and promote prudence and wholesomeness for all (Dion, 2012). Applying a virtue ethics principle to ethical decision-making requires action, as virtue is neither innate, nor acquired by thought, abstinence or restraint (Dion, 2012). Since as DeGeorge (2010) observes, we are not born with virtue but become virtuous through habitual actions, the virtue ethics principle dictates the motive for doing right is to become good. 


\section{Institutional Values}

This study was conducted at a Jesuit, Catholic institution, because Jesuit education is built on a commitment to institutional mission that has ties to the practice of student affairs administration (Stringer \& Swezey, 2006). Six core institutional values formed the framework for coding participants' ethical decision-making rationales. While these six institutional values reflect the unique mission of the study institution, they are indicative of the emphasis placed on character-building among all institutions of higher education (Mayhew et al., 2016).

The following conceptual definitions of the six institutional values were used to code the ethical decision-making rationales elicited from participants in this study:

\section{Reflection}

Reflection invites individuals to "pause and consider the world around them and their place within it" (Center for Mission \& Identity, 2017). Operationally, reflection involves looking back to understand where we are and where we are going in life; remembering what has been in order to determine how to move forward.

\section{Discernment}

Discernment invites individuals to "be open to new insights... in order to make decisions and take actions that will contribute good to the universe and all those in it" (Center for Mission \& Identity, 2017). Discernment involves giving careful consideration to discovering what brings meaning and purpose to life as a guide for making decisions.

\section{Solidarity and Kinship}

Solidarity and kinship invites individuals to "identify with and consider their commonality with all others" (Center for Mission \& Identity, 2017). Solidarity and Kinship requires standing with others through good times and bad, listening and being present.

\section{Service Rooted in Justice and Love}

Service rooted in justice and love invites individuals to "invest their lives in actions that promote the well-being of others, particularly those who suffer injustice" (Center for Mission \& Identity, 2017). It manifests in actions carried out to better the lives of individuals and communities, enabling and empowering others not for the sake of reward or recognition, or with an intent to fix something.

\section{Cura Personalis}

The translation of Cura Personalis, "care for the whole person," invites individuals "to recognize and cherish the uniqueness of others, and to care for the wholeness of each person mind, body and spirit" (Center for Mission \& Identity, 2017). The essence of Cura Personalis is to take actions that promote others' social, academic, mental and spiritual well-being.

\section{Magis}

The literal translation of Magis, "the more", invites individuals to consider, "Where is the more universal good?" when making decisions and choosing their actions and contributions in the world (Center for Mission \& Identity, 2017). Reflecting Magis involves manifesting a spirit of generosity, excellence and continuous improvement in all aspects of life.

\section{METHODOLOGY}

Data for this mixed-methods study included narrative (qualitative) and survey (quantitative) responses to five hypothetical scenarios representing ethical dilemmas a typical college student might encounter (See Appendixes A \& B). Responses were solicited from incoming first-year undergraduates prior to 
matriculation, and from graduating seniors in their final semester. First-year students were assessed prior to matriculation to minimize their exposure to institutional values; graduating seniors had to have been enrolled for at least 3 years, and satisfy Astin's (1984) rule of three for operationalizing campus involvement. A random sample of 300 eligible seniors and 300 incoming first-year students were sent an email containing a link to Qualtrics where the ethical scenarios were presented. All responses were anonymous; a three-week response window was provided with weekly reminders to participate.

\section{Instrumentation}

The response protocol first asked students to describe what actions they would take if faced with the situation described in the ethical scenarios, and to provide a rationale explaining the reasons for their actions (see Appendix A). After providing narrative responses to all five hypothetical scenarios, students responded to 12 Likert-style questions rating the degree to which they considered each ethical principle and institutional value in responding to each scenario (see Appendix B). These procedures captured participants' native responses and rationales, prior to soliciting normative responses on the Likert survey (Whitley \& Kite, 2013). Limited demographic data were collected to facilitate data analysis and interpretation. The response protocol was piloted prior to distribution.

\section{Data Analysis}

Content analysis of narrative responses was completed prior to statistical analysis of survey responses. Narrative responses to the ethical scenarios were coded to reflect the ethical principles and institutional values outlined in the theoretical framework, using a two-step process: First the two coinvestigators independently assigned codes, then these code assignments were reviewed by two sets of experts: ethics scholars reviewed the assignment of ethical principles, and Jesuit scholars reviewed the assignment of institutional values. After coding, results were reviewed for patterns in the ethical decisionmaking of each student population; results of the two groups were then compared. Repeated-measures analysis of variance (ANOVA-RM) was used to analyze responses to the Likert-style survey. Use of this statistic was warranted because participants provided multiple responses to each of the six scenarios and served to reduce the risk of Type I errors (i.e. falsely claiming statistical difference) (Statistics Solutions, 2018). Assumptions of the statistical procedure were met.

\section{RESULTS}

Usable responses to the qualitative assessment were obtained from 30 first-year students and 28 seniors; a total of 27 students in both groups completed the quantitative assessment. This exceeded the target number of responses established for the study, given the extended, open-ended, narrative responses required. The gender breakdown of respondents was $63 \%$ female for both groups, $63 \%$ (first-year) vs. $66 \%$ (seniors) white, and 33\% (first-year) vs. 37\% (seniors) Catholic. These demographic data were generally representative of the institution's most recent census data which reported the undergraduate population to be: $54 \%$ female, $76 \%$ white and 52\% Roman Catholic (Institutional Research, 2018).

\section{Qualitative Analysis of Narrative Responses}

After coding the narrative responses to each of the 5 ethical scenarios, code frequencies were calculated indicating the number of responses reflecting each ethical principle and institutional value. The ethical principles and institutional values were then ranked within each scenario from high (6) to low (1), denoting which codes were most frequently employed in response to that ethical dilemma. Results of these frequency and rank order calculations are presented in the "Coded" rows of Tables 1 (ethical principles) \& 2 (values). 


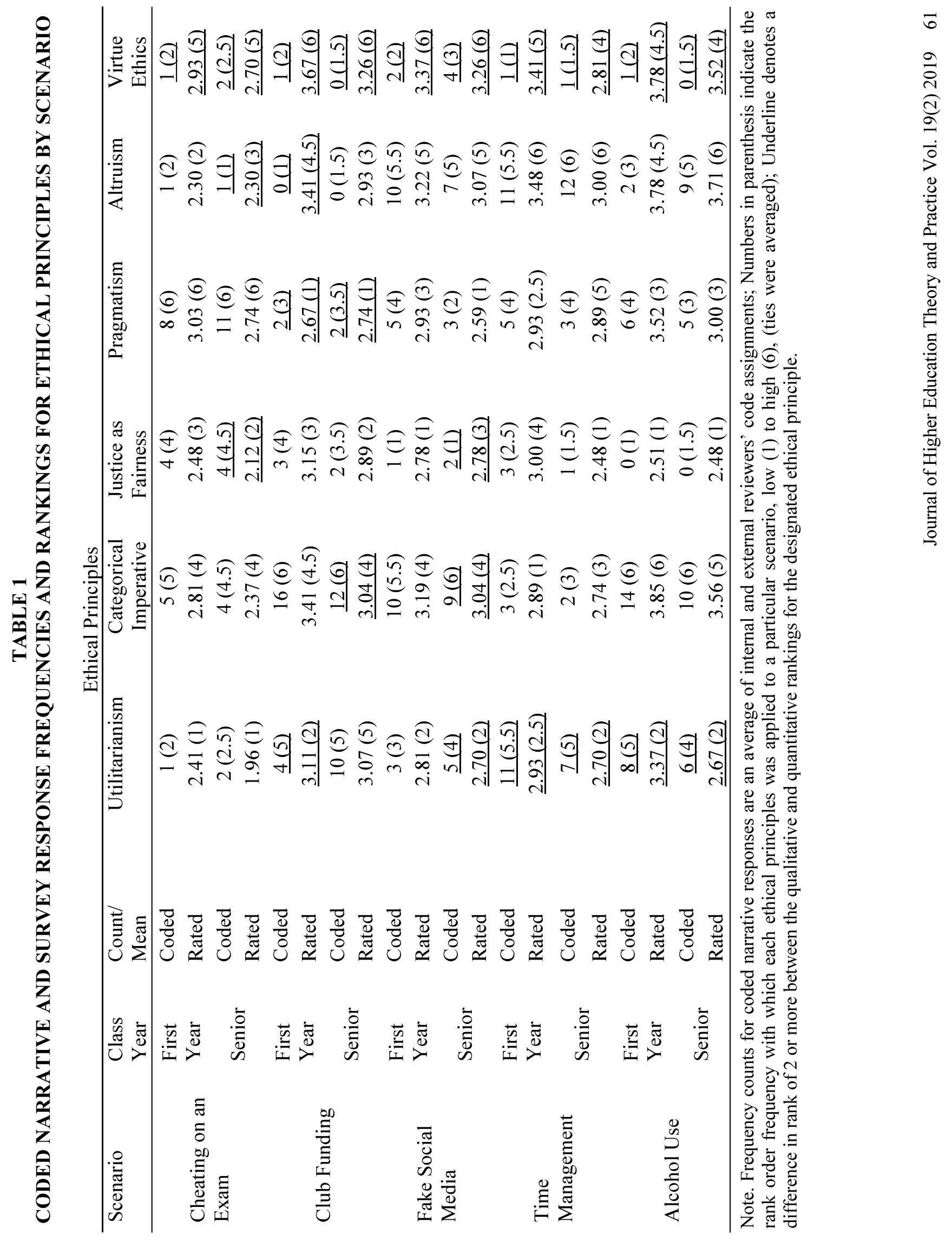




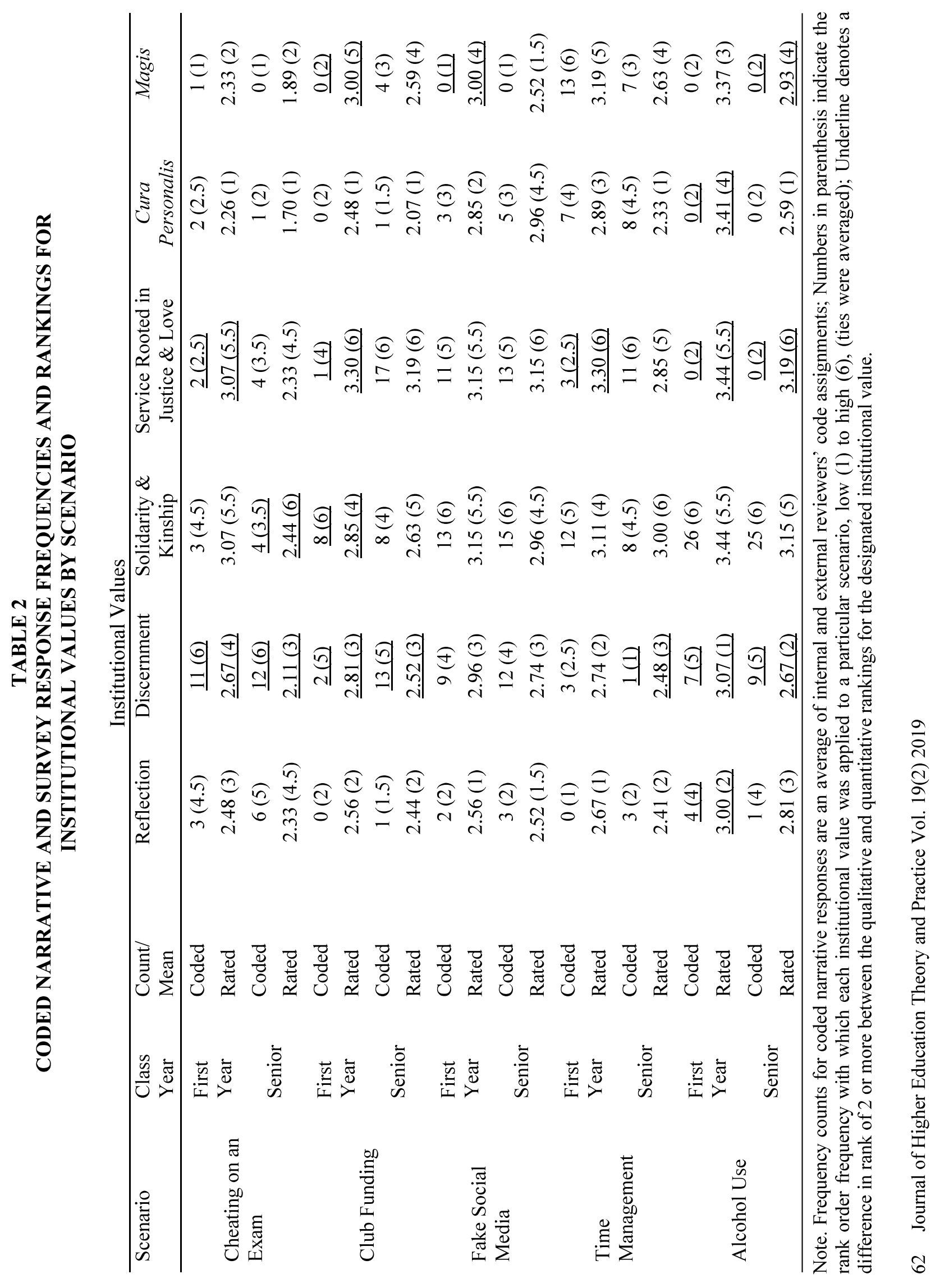




\section{TABLE 3 \\ MAIN EFFECTS RESULTING FROM REPEATED MEASURES ANOVAS}

\begin{tabular}{|c|c|c|}
\hline Ethical Scenarios & Ethical Principles & Institutional Values \\
\hline \\
\hline \multicolumn{2}{|c|}{ Within-subjects effect $\quad F(3.97,206.27)=5.69, p<.001$} & $\mathrm{~F}(3.91,203.40)=7.05, \mathrm{p}<.001$ \\
\hline \multicolumn{2}{|c|}{ Between-subjects effect $\quad F(3.97,206.27)=.46$, n.s. } & $\begin{aligned} & \mathrm{F}(1,52)=6.42, \mathrm{p}<.05 \\
\mathrm{FY} & =2.65 ; \mathrm{SY}_{\text {mean }}=2.14\end{aligned}$ \\
\hline \multicolumn{3}{|l|}{ Use of Club Funding } \\
\hline Within-subjects effect & $\mathrm{F}(4.27,221.84)=5.29, \mathrm{p}<.001$ & $\mathrm{~F}(5,260)=7.84, \mathrm{p}<.001$ \\
\hline Between-subjects effect & $\mathrm{F}(1,52)=2.421, \mathrm{n} . \mathrm{s}$ & $\mathrm{F}(1,52)=1.45$, n.s. \\
\hline \multicolumn{3}{|l|}{ Fake Social Media } \\
\hline Within-subjects effect & $\mathrm{F}(4.21,218.79)=5.30, \mathrm{p}<.001$ & $\mathrm{~F}(5,260)=3.45, \mathrm{p}=.005$ \\
\hline Between-subjects effect & $\mathrm{F}(1,52)=.583$, n.s. & $\mathrm{F}(1,52)=.98$, n.s. \\
\hline \multicolumn{3}{|l|}{ Time Management } \\
\hline Within-subjects effect & $\mathrm{F}(5,260)=2.83, \mathrm{p}=.017$ & $\mathrm{~F}(5,260)=4.28, \mathrm{p}=.005$ \\
\hline \multirow[t]{2}{*}{ Between-subjects effect } & $\mathrm{F}(1,52)=4.23, \mathrm{p}=.044$ & $\mathrm{~F}(1,52)=3.01$, n.s. \\
\hline & $\mathrm{FY}_{\text {mean }}=3.11 ; \mathrm{SY}_{\text {mean }}=2.77$ & \\
\hline \multicolumn{3}{|l|}{ Underage Alcohol Use } \\
\hline Within-subjects effect & $\mathrm{F}(3.97,206.24)=18.03$ & $\mathrm{~F}(5,260)=2.68, \mathrm{p}=.022$ \\
\hline \multirow[t]{2}{*}{ Between-subjects effect } & $F(1,52)=6.17, p=.016$ & $\mathrm{~F}(1,52)=4.27, \mathrm{p}=.044$ \\
\hline & $\mathrm{FY}_{\text {mean }}=3.47 ; \mathrm{SY}_{\text {mean }}=3.15$ & $\mathrm{FY}_{\text {mean }}=3.29 ; \mathrm{SY}_{\text {mean }}=2.89$ \\
\hline Ethical Principles & Ethical Scenarios & \\
\hline \multicolumn{3}{|l|}{ Utilitarianism } \\
\hline Within-subjects effect & $\mathrm{F}(4,208)=8.97, \mathrm{p}<.001$ & \\
\hline Between-subjects effect & $\mathrm{F}(1,52)=2.75$, n.s. & \\
\hline \multicolumn{3}{|l|}{ Categorical Imperative } \\
\hline Within-subjects effect & $\mathrm{F}(4,208)=17.88, \mathrm{p}<.001$ & \\
\hline Between-subjects effect & $\mathrm{F} 1,52)=3.09$, n.s. & \\
\hline \multicolumn{3}{|l|}{ Justice as Fairness } \\
\hline Within-subjects effect & $\mathrm{F}(3.43,178.32)=5.78, \mathrm{p}<.001$ & \\
\hline Between-subjects effect & $\mathrm{F}(1,52)=1.05$, n.s. & \\
\hline \multicolumn{3}{|l|}{ Pragmatism } \\
\hline Within-subjects effect & $\mathrm{F}(3.32,172.62)=4.60, \mathrm{p}<.001$ & \\
\hline Between-subjects effect & $\mathrm{F}(1,52)=1.004$, n.s. & \\
\hline \multicolumn{3}{|l|}{ Altruism } \\
\hline Within-subjects effect & $\mathrm{F}(4,208)=24.49, \mathrm{p}<.001$ & \\
\hline Between-subjects effect & $\mathrm{F}(1,51)=2.49$, n.s. & \\
\hline \multicolumn{3}{|l|}{ Virtue Ethics } \\
\hline Within-subjects effect & $\mathrm{F}(3.21,166.78)=9.86, \mathrm{p}<.001$ & \\
\hline Between-subjects effect & \multicolumn{2}{|c|}{$\mathrm{F}(1,52)=4.14, \mathrm{p}=.047\left(\mathrm{FY}_{\text {mean }}=3.43 ; \mathrm{SY}_{\text {mean }}=3.11\right)$} \\
\hline Institutional Values & Ethical Scenarios & \\
\hline \multicolumn{3}{|l|}{ Reflection } \\
\hline Within-subjects effect & $\mathrm{F}(3.40,176.66)=3.91, \mathrm{p}<.007$ & \\
\hline \multirow{2}{*}{\multicolumn{3}{|c|}{ Discernment }} \\
\hline & & \\
\hline Within-subjects effect & $\mathrm{F}(2.79,144.80)=4.71, \mathrm{p}<.005$ & \\
\hline Between-subjects effect & $\mathrm{F}(1,52)=1.93$, n.s. & \\
\hline \multicolumn{3}{|l|}{ Solidarity \& Kinship } \\
\hline Within-subjects effect & $\mathrm{F}(3.41,177.38)=5.61, \mathrm{p}<.001$ & \\
\hline Between-subjects effect & $\mathrm{F}(1,52)=1.42$, n.s. & \\
\hline Service Rooted in Justice \& Love & & \\
\hline Within-subjects effect & $\mathrm{F}(3.38,176.04)=4.97, \mathrm{p}<.002$ & \\
\hline Between-subjects effect & $\mathrm{F}(1,52)=2.60$, n.s. & \\
\hline Cura Personalis (care for the whol & erson) & \\
\hline Within-subjects effect & $\mathrm{F}(4,208)=16.31, \mathrm{p}<.001$ & \\
\hline Between-subjects effect & $\mathrm{F}(1,52)=4.43, \mathrm{p}=.04\left(\mathrm{FY}_{\text {mean }}=\right.$ & $\left.\mathrm{SY}_{\text {mean }}=2.26\right)$ \\
\hline Magis (the more) & & \\
\hline Within-subjects effect & $F(4,208)=17.70, p<.001$ & \\
\hline Between-subjects effect & $\mathrm{F}(1,52)=3.54$, n.s. & \\
\hline
\end{tabular}




\section{Patterns in the Use of Ethical Principles}

Clear patterns of variation emerged with respect to the ethical principles reflected in participants' narrative responses (see Table 1). Rather than adopting one favored or characteristic response to all ethical situation, responses demonstrated a strong situational influence in determining which ethical principle was applied by participants' in each ethical scenario. Kant's categorical imperative was applied most frequently overall by both participant groups, ranking among the top two principles applied by firstyear students in 4 of the 5 scenarios, and 3 of 5 scenarios by seniors. Both student groups favored the categorical imperative in responding to club funding, fake social media and under-aged alcohol use; and first-year students did so in responding to cheating on an exam. The next most frequently employed ethical principles were utilitarianism and altruism, applied by both first-year and senior students in 2 of 5 ethical dilemmas. Utilitarianism was most frequently applied by first-year students in the time management and under-aged alcohol use scenarios, and by seniors in time management and club funding. Altruism was most frequently applied by first-year students to dealing with fake social media and time management, and by seniors to time management and under-aged alcohol use. Pragmatism was the most frequent ethical principle applied by both student groups in response to cheating on an exam. The pattern was similar for both student groups.

\section{Patterns in the Application of Institutional Value}

Clear patterns of variation also emerged in the institutional values reflected in participants' responses to the ethical scenarios (see Table 2). Discernment ranked among the top two values applied by both student groups to 3 scenarios: cheating on an exam, club funding and under-aged alcohol use. Among first-year students, solidarity and kinship was also among the top two responses, reflected in 4 of 5 scenarios (club funding, fake social media, time management and under-aged alcohol use), but only 2 scenarios for seniors (fake social media and under-aged alcohol use). Senior's ethical decision-making reflected more emphasis on service rooted in love and mercy in 3 of 5 scenarios (club funding, fake social media, time management), compared to only 1 scenario first-year students (fake social media). Finally, Magis and reflection were only prevalent among first-year students' responses to time management and cheating on an exam, while Cura Personalis was not prevalent among either student group's responses. Overall, graduating seniors surpassed first-year students in applying institutional values to 3 of the 5 categories, and tied in the other 2 . This differential was most evident in the club funding scenario, where seniors' responses reflected $65 \%$ more institutional values than first-year students (52 compared to 11 , respectively).

\section{Quantitative Analysis of Survey Responses}

Results of the ANOVA-RM analysis revealed the effect of first-year vs. senior class year on the extent to which each ethical principle and institutional value was considered in responding to the ethical scenarios. This statistic was also used to assess whether class year had an overall effect on the application of each ethical principle and institutional value to the ethical scenarios. Mauchly's test of sphericity was applied to each ANOVA; if sphericity was rejected, the Greenhouse-Geisser correction was applied in determining overall significance. Interaction effects were also calculated. Main effects resulting from these analyses are summarized in Table 3.

\section{Cheating on an Exam}

In assessing the differential consideration afforded each ethical principle in responding to the cheating on an exam scenario, the within-subjects effect for ethical principles was statistically significant, $\mathrm{F}(3.97,206.27)=5.69, \mathrm{p}<.001$, but the between-subjects effect of student class year was not, $\mathrm{F}(1,52)=$ $2.50, \mathrm{p}=.120$ Mauchly's test of sphericity was rejected, $\mathrm{W}_{\text {Mauchly's }}(14)=.562, \mathrm{p}=.011$, so the Greenhouse-Geisser correction $(\varepsilon=.79)$ was applied. There was no interaction between student class and ethical principles, $\mathrm{F}(3.97,206.27)=.46, \mathrm{p}=.77$. Post hoc Bonferroni analysis revealed students were more likely to take a pragmatic or virtue ethics approach to decision making than to consider the greater good for all (utilitarianism), justice as fairness or altruism. In assessing the effect of institutional values on 
ethical decision-making relative to cheating on an exam, both the within-subjects effect for institutional values, $\mathrm{F}(3.91,203.40)=7.05, \mathrm{p}<.001$, and the between-subjects effect of student class year, $\mathrm{F}(1,52)=$ $6.42, \mathrm{p}=.014$, were statistically significant, but there was no significant interaction between student class and institutional values, $\mathrm{F}(3.91,203.40)=.76, \mathrm{p}=.55$. Mauchly's test of the sphericity assumption was rejected, $\mathrm{W}_{\text {Macuhly's }}(14)=.45, \mathrm{p}<.001$, so the Greenhouse-Geisser correction $(\varepsilon=.78)$ was applied. The between-subjects effect revealed first-year students $(M=2.65)$ reported considering institutional values to a greater degree than senior students in responding to the cheating on an exam scenario, $(\mathrm{M}=2.14)$, mean difference $=.51, \mathrm{p}=.014$. Post hoc Bonferroni analysis of pairwise comparisons applied to the withinsubjects analysis revealed students were more likely to consider discernment, solidarity and kinship, or service rooted in justice and love than Cura Personalis, and were more likely to act with solidarity and kinship, or service rooted in justice and love, than Magis. .

\section{Use of Club Funding}

Analysis of the ethical principles considered in responding to the club funding scenario revealed no main effect for class year (first vs. senior) $F(1,52)=2.421, p=.126$, but the within subjects effect for ethical principles was statistically significant, $\mathrm{F}(4.27,221.84)=5.29, \mathrm{p}<.001$ Mauchly's test of sphericity was rejected, $\mathrm{W}_{\text {Mauchly's }}(14)=.612, \mathrm{p}=.039$, so the Greenhouse-Geisser correction $(\varepsilon=.85)$ was applied. There was no significant interaction between student class year and ethical principles, $\mathrm{F}(4.27,221.84)=1.024, \mathrm{p}=.398$. Post hoc Bonferroni test of pairwise comparisons revealed students were more likely to employ a categorical imperative or virtue ethics approach to the use of club funding scenario than to utilize a pragmatic approach. In assessing the effect of institutional values on ethical decision-making relative to the use of club funding, the within-subjects effect for institutional values was statistically significant, $F(5,260)=7.84, p<.001$; but the between-subjects effect of student class year was not, $\mathrm{F}(1,52)=1.45, \mathrm{p}=.23$. The interaction of student class and institutional values was not significant, $\mathrm{F}(5,260)=.34, \mathrm{p}=.89$. Post hoc Bonferroni assessment of pairwise comparisons found students gave more consideration to service rooted in justice and love than any other institutional value, and were less likely to consider Cura Personalis than solidarity and kinship or Magis.

\section{Fake Social Media}

In responding to the fake social media scenario, the within-subjects effect for ethical principles was statistically significant, $\mathrm{F}(4.21,218.79)=5.30, \mathrm{p}<.001$, but the between-subjects effect of student class year was not, $\mathrm{F}(1,52)=.583, \mathrm{p}=.45$ Mauchly's test of sphericity was rejected, $\mathrm{W}_{\text {Mauchly's }}(14)=.58, \mathrm{p}=$ .019 , so the Greenhouse-Geisser correction $(\varepsilon=.84)$ was applied. The interaction of student class year and ethical principles was not significant, $\mathrm{F}(4.21,218.79)=.263, \mathrm{p}=.91$. Post hoc Bonferroni analysis revealed students were more likely to use a virtue ethics approach in addressing use of fake social media, than a utilitarian, justice, or pragmatic approach. In assessing the effect of institutional values on ethical decision-making relative to the fake social media scenario, the within-subjects effect for institutional values was statistically significant, $\mathrm{F}(5,260)=3.45, \mathrm{p}=.005$, but the between-subjects effect of student class year was not, $\mathrm{F}(1,52)=.98, \mathrm{p}=.33$. The interaction of student class and institutional values was not significant, $\mathrm{F}(5,260)=.51, \mathrm{p}=.77$. Post hoc Bonferroni test of pairwise comparisons revealed more consideration for service rooted in justice in love than reflection.

\section{Time Management}

With respect the time management scenario, both the within-subjects effect for ethical principles, $\mathrm{F}(5$, $260)=2.83, p=.017$, and the between-subjects effect for class year, $F(1,52)=4.23, p=.044$ were significant, though there was no significant interaction between student class year and ethical principles, $\mathrm{F}(5,260)=.95, \mathrm{p}=.45$. The between-subjects effect revealed first-year students $(\mathrm{M}=3.11)$ reported considering ethical principles to a greater degree than senior students $(\mathrm{M}=2.77)$, mean difference $=.33, \mathrm{p}$ $=.04$. Post hoc Bonferroni test found no significant pair-wise comparisons suggesting the differences were too small for the relatively strict Bonferroni statistic to accurately detect in a small sample. Since using a less conservative post hoc statistic such as Tukey's to located pair-wise differences is not 
recommended with repeated measures because it risks returning a Type I error (Cardinal \& Aitken, 2006), the inconclusive results of the Bonferroni post hoc analysis were accepted. In assessing the effect of institutional values on ethical decision-making relative to the time management scenario, the withinsubjects effect for institutional values was statistically significant, $F(5,260)=4.28, p=.005$; but the between-subjects effect of student class year was not, $\mathrm{F}(1,52)=3.01, \mathrm{p}=.088$. The interaction of class year and institutional values was not significant, $\mathrm{F}(5,260)=.61, \mathrm{p}=.695$. A post hoc Bonferroni test revealed more consideration for service rooted in justice and love than either reflection or discernment.

\section{Underage Alcohol Use}

With respect to under-age alcohol use scenario, both the within-subject effect for ethical principle, $\mathrm{F}(3.97,206.24)=18.03, \mathrm{p}<.00$ and the between-subjects effect of student class year were significant, $\mathrm{F}(1,52)=6.17, \mathrm{p}=.016$, though there was no significant interaction between student class year and ethical principles, $\mathrm{F}(3.97,206.24)=1.25, \mathrm{p}=.29$. Mauchly's test of sphericity was rejected, $\mathrm{W}_{\text {Mauchly's }}$ $(14)=.413, \mathrm{p}<.00$, so with the Greenhouse-Geisser correction $(\varepsilon=.96)$ was applied. The betweensubjects effect revealed first-year students $(\mathrm{M}=3.47)$ reported considering ethical principles in relation to under-aged alcohol use more than seniors $(\mathrm{M}=3.15)$, mean difference $=.32, \mathrm{p}=.016$. Post hoc Bonferroni assessment found students applied virtue ethics, pragmatism, categorical imperative, and altruism more than utilitarianism or justice as fairness. In applying institutional values to ethical decisionmaking relative to underage alcohol use both the within-subjects effect for institutional values, $\mathrm{F}(5,260)$ $=2.68, \mathrm{p}=.022$ and between-subjects effect of student class year were significant, $\mathrm{F}(1,52)=4.27, \mathrm{p}=$ .044 . First-year students $(\mathrm{M}=3.29)$ reported considering institutional values more than seniors $(\mathrm{M}=$ 2.89), mean difference $=.40, \mathrm{p}=.04$, with no significant interaction effect, $\mathrm{F}(5,260)=.90, \mathrm{p}=.48$. Post hoc Bonferroni test of pairwise comparisons found students were more likely to reflect the institutional value service rooted in justice and love than discernment in responding to underage alcohol use.

\section{Utilitarianism}

ANOVA-RM was also used to determine the effect of class year on the degree to which each ethical principle was considered in responding to each of the ethical scenarios. With respect to utilitarianism, the within-subjects effect for ethical scenario was statistically significant, $F(4,208)=8.97, p<.001$, but the between-subjects effect of student class year was not, $\mathrm{F}(1,52)=2.75, \mathrm{p}=.103$, and there was no significant interaction effect, $\mathrm{F}(4,208)=1.295, \mathrm{p}=.27$. Post hoc Bonferroni test found students applied utilitarianism significantly less to cheating on an exam than to other ethical scenarios.

\section{Kant's Categorical Imperative}

With respect to the application of Kant's categorical imperative, the within-subjects effect for ethical scenario was statistically significant, $\mathrm{F}(4,208)=17.88, \mathrm{p}<.00$, but the between-subjects effect of student class year was not, $F 1,52)=3.09, \mathrm{p}=.085$, and there was no significant interaction effect, $\mathrm{F}(4,208)=$ $.437, \mathrm{p}=.78$. Post hoc Bonferroni test of pairwise comparisons revealed students applied the categorical imperative to underage alcohol use more than to all other scenarios, and applied it to club funding more than cheating on an exam and time management; to fake social media more than cheating on an exam; and to use of club funding more than time management.

\section{Justice as Fairness (Ethical Principle, Omnibus Effect)}

With respect to applying justice as fairness, the within-subjects effect for hypothetical scenario was statistically significant, $\mathrm{F}(3.43,178.32)=5.78, \mathrm{p}<.00$, but the between-subjects effect of student class year was not, $\mathrm{F}(1,52)=1.05, \mathrm{p}=.31$, and there was no significant interaction effect, $\mathrm{F}(3.42,178.32)=$ $.92, \mathrm{p}=.44$. Mauchly's test of sphericity was rejected, $\mathrm{W}_{\text {Mauchly's }}(9)=.69, \mathrm{p}=.026$, so the GreenhouseGeisser correction $(\varepsilon=.857)$ was applied. Post hoc Bonferroni assessment test of pairwise comparisons revealed students applied justice as fairness to the use of club funding more than to cheating on an exam or underage alcohol use. 


\section{Pragmatism}

With respect to pragmatism, the within-subjects effect for hypothetical scenario was statistically significant, $\mathrm{F}(3.32,172.62)=4.60, \mathrm{p}=.001$, but the between-subjects effect of student class year was not, $\mathrm{F}(1,52)=1.004, \mathrm{p}=.321$, and there was no significant interaction effect, $\mathrm{F}(3.32,172.62)=1.397, \mathrm{p}=$ 2.43. Mauchly's test of sphericity was rejected, $\mathrm{W}_{\text {Mauchly's }}(9)=.497, \mathrm{p}<.00$, so the Greenhouse-Geisser correction $(\varepsilon=.83)$ was applied. Post hoc Bonferroni assessment revealed students applied pragmatism to underage alcohol use more than to the use of club funding and fake social media.

\section{Altruism}

With respect to altruism, the within-subjects effect for ethical scenario was statistically significant, $\mathrm{F}(4,208)=24.49, \mathrm{p}<.001$, but the between-subjects effect of student class year was not, $\mathrm{F}(1,51)=2.49$, $\mathrm{p}=.121$, and there was no significant interaction effect, $\mathrm{F}(4.208)=1.19, \mathrm{p}=.316$. Post hoc Bonferroni test of pairwise comparisons revealed students applied altruism to underage alcohol use more than to all other scenarios, and to cheating on an exam less than all other scenarios.

\section{Virtue Ethics}

With respect virtue ethics, both the within-subjects effect for ethical scenario, $F(3.21,166.78)=9.86$, $\mathrm{p}<.000$, and the between-subjects effect of student class year, $\mathrm{F}(1,52)=4.14, \mathrm{p}=.047$, were significant, but there was no significant interaction effect, $\mathrm{F}(3.21,166.78)=.825, \mathrm{p}=.489$. Mauchly's test of sphericity was rejected, $\mathrm{W}_{\text {Mauchly's }}(9)=.61, \mathrm{p}=.003$, so the Greenhouse-Geisser correction $(\varepsilon=.802)$ was applied. First-year students $(M=3.43)$ considered virtue ethics more than seniors $(M=3.11)$, mean difference $=.32, \mathrm{p}=.047$. Post hoc Bonferroni test of pairwise comparisons indicated students applied virtue ethics to underage alcohol use more than to cheating on an exam, fake social media, and time management. They applied virtue ethics less to cheating on an exam than all other scenarios except time management, and to use of club funding more than to time management.

\section{Reflection}

With respect to the institutional value reflection, the within-subjects effect for ethical scenario was statistically significant, $\mathrm{F}(3.40,176.66)=3.91, \mathrm{p}=.007$, but the between-subjects effect of student class year was not, $F(1,52)=.34, p=.56$, and there was no significant interaction effect, $F(4,208)=.182, p=$ .93. Mauchly's test of sphericity was rejected, $\mathrm{W}_{\text {Mauchly's }}(9)=.61, \mathrm{p}=.003$, so the Greenhouse-Geisser correction $(\varepsilon=.85)$ was applied. Results indicate first-year and senior students did not differ in their consideration of reflection in making ethical decisions. Post hoc Bonferroni assessment found students applied reflection more to the underage alcohol use scenario, than to cheating on an exam.

\section{Discernment}

With respect to discernment, the within-subjects effect for ethical scenario was significant, $\mathrm{F}(2.79$, $144.80)=4.71, \mathrm{p}=.005$, but the between-subjects effect of student class year was not, $\mathrm{F}(1,52)=1.93, \mathrm{p}$ $=.17$, and there was no significant interaction effect, $F(2.79,144.80)=.55, p=.63$. Mauchly's test of sphericity was rejected, $\mathrm{W}_{\text {Mauchly's }}(9)=.46, \mathrm{p}<.00$, so the Greenhouse-Geisser correction $(\varepsilon=.696)$ was applied, Post hoc Bonferroni assessment revealed students applied discernment to the fake social media scenario more than to cheating on an exam.

\section{Solidarity and Kinship}

With respect to solidarity and kinship, the within-subjects effect for ethical scenario was statistically significant, $\mathrm{F}(3.41,177.38)=5.61, \mathrm{p}=.001$, but the between-subjects effect of student class year was not, $\mathrm{F}(1,52)=1.42, \mathrm{p}=.24$, and there was no significant interaction effect, $\mathrm{F}(2.79,144.80)=1.05, \mathrm{p}=.38$. Mauchly's test of sphericity was rejected, W Wauchly's $(9)=.67, p=.015$, so the Greenhouse-Geisser correction $(\varepsilon=.85)$ was applied Post hoc Bonferroni test of pairwise comparisons revealed students applied solidarity and kinship to under-aged alcohol scenario more than to either cheating on an exam or use of club funding. 


\section{Service Rooted in Justice and Love}

With respect to service rooted in justice and love, the within-subjects effect for ethical scenario was statistically significant, $\mathrm{F}(3.38,176.04)=4.97, \mathrm{p}=.002$, but the between-subjects effect of student class year was not, $\mathrm{F}(1,52)=2.60, \mathrm{p}=.113$, and there was no significant interaction effect, $\mathrm{F}(3.38,176.04)=$ $1.88, \mathrm{p}=.13$. Mauchly's test of sphericity was rejected, $\mathrm{W}_{\text {Mauchly's }}(9)=.67, \mathrm{p}=.016$, so the GreenhouseGeisser correction $(\varepsilon=.85)$ was applied Post hoc Bonferroni test of pairwise comparisons revealed students applied service rooted in justice and love more to the club funding and under-age alcohol scenarios than to cheating on an exam.

\section{Cura Personalis}

With respect to Cura Personalis, both the within-subjects effect for ethical scenario, $\mathrm{F}(4,208)=$ $16.31, \mathrm{p}<.000$, and the between-subjects effect for student class year, $\mathrm{F}(1,52)=4.43, \mathrm{p}=.04$ were significant, but there was no significant interaction effect, $\mathrm{F}(4,208)=1.10, \mathrm{p}=.36$. First-year students $(\mathrm{M}=2.78)$ reported considering Cura Personalis to a greater degree than senior students $(\mathrm{M}=2.26)$, mean difference $=.54, \mathrm{p}=.04$. Post hoc Bonferroni analysis revealed students applied Cura Personalis more to the under-age alcohol scenario than to cheating on an exam, use of club funding, or time management, but less than to fake social media and time management, and more to the fake social media scenario than to club funding.

Magis

With respect to Magis, the within-subjects effect for hypothetical scenario was statistically significant, $\mathrm{F}(4,208)=17.70, \mathrm{p}<.000$, but the between-subjects effect of student class year was not, $\mathrm{F}(1$, $52)=3.54, \mathrm{p}=.07$, and there was no significant interaction effect, $\mathrm{F}(4,208)=.094, \mathrm{p}=.98$. Post hoc Bonferroni analysis revealed students reported applying Magis to the cheating on an exam scenario less than to all other scenarios, and to under-age alcohol use than to club funding and fake social media.

\section{Triangulation of Results: Comparison of Qualitative and Quantitative Data}

The final step of data analysis involved triangulating results by comparing outcomes of the quantitative analyses to the qualitative findings discussed previously. The purpose of comparing results of the qualitative and quantitative analyses obtained in this study was to determine whether participant's subjective, self-reported ratings were in agreement with the researchers' and external experts' objective coding of participants' narrative responses to each of the ethical scenarios. Such triangulation of qualitative and quantitative results lends credibility to the analysis of case study research conducted with small numbers of participants (Whitley \& Kite, 2013). To facilitate this analysis, the means of survey responses (with rankings in parentheses) were added to the counts and rankings of coded narrative responses in Tables $1 \& 2$.

Table 1 presents the results of this comparative analysis for participants' application of ethical principles. Table 2 presents the result of this comparative analysis for participants' consideration of institutional values in their responses to the ethical scenarios. As before, rank order was assigned, within each scenario, from the lowest (1) mean to the highest (6). In accordance with standard practice, codes or means that were equivalent were averaged, i.e. if the code or mean for two or more responses was equal, the average for those responses was assigned to each. The rankings of the coded responses and mean ratings is compared in the analysis that follows for each ethical principle and each institutional value, broken down by class year (first-year vs senior) and ethical scenario.

The overview of both datasets provided in Tables $1 \& 2$ reveal the coded narrative responses and the survey responses largely align, although some differences were observed, as discussed below. The comparisons provide evidence that context matters in how students applied ethical principles and institutional values in making ethical decisions. In other words, participants varied the way they made ethical decisions based on the particular context of the dilemma presented. Circumstances unique to each scenario determined the frequency with which participants applied each of the ethical principles and institutional values, and this was true for both first-year and senior students. Rather than adopting one 
approach to ethical decision making, students demonstrated the capacity to consider elements of each specific situation and the flexibility to adjust this ethical decision-making to bet suit the circumstances.

\section{Triangulation of Ethical Principles Data}

Further analysis of the qualitative and quantitative data consolidated in Table 1 reveals nuances of situational variability in how study participants applied ethical principles in making ethical decisions. Overall, utilitarianism ranked on the low end of reported (i.e. survey) responses, but the higher end of coded (i.e. narrative) responses, while virtue ethics ranked higher for reported responses than for coded responses. Greater alignment of qualitative and quantitative data was observed in the rankings for the other ethical principles: categorical imperative, justice as fairness, pragmatism, and altruism. Across the scenarios, the least agreement between coded responses and reported responses was observed for the $c l u b$ funding and time management scenarios. Fake social media resulted in less agreement among senior students' responses, but almost full agreement, with the exception of virtue ethics, for first-year students.

Closer analysis of these data, particularly focusing on where there were discrepancies in the rankings, revealed the greatest misalignment occurred in relation to virtue ethics, where the means and rankings of the survey data were higher than the coded narrative responses. This suggests that when responding to the survey students reported they "chose actions that promoted moral goodness for all," much more frequently than was observed in the narrative rationales provided by these same participants. This discrepancy between students' ratings and coded responses for the application of virtue ethics was observed for both first-year and senior students, and held true across all ethical scenarios, raising the possibility students view themselves behaving more virtuously than their actions convey. Discrepancies were also evident among both first-year and senior students in the rankings for utilitarianism, demonstrating students reported considering the greatest good for the greatest number of people to a lesser degree than was observed in their narrative responses.

A comparison of qualitative and quantitative data also revealed areas of consistency across survey and narrative data. Both first-year and senior students applied the categorical imperative principle more in responding to some ethical scenarios than others, suggesting both student groups adhered to ethical norms more in some situations, such as under aged alcohol use and misuse of club funding, than in others. Pragmatism was consistently evidenced by both survey and narrative responses to be applied most frequently to the cheating on an exam scenario by both first-year and senior students, and altruism was consistently applied most often to the time management scenario by both student groups. Similarly, application of the ethical principle justice as fairness was neither observed nor reported to be extensively employed in response to any ethical scenario, by either student group.

Finally, comparisons of the data pertaining to the application of ethical principles were reviewed in light of the statistically significant results of the repeated measures analysis, to determine if qualitative results corroborated the quantitative findings. With respect to the ethical principles, significant betweengroups results were obtained from the repeated measures ANOVAs indicating a significant difference between first-year and senior students with respect to considering ethical principles in response to the time management and under-aged alcohol scenarios, with first-year students considering all ethical principles more than seniors. The coded data for time management corroborated this finding for all ethical principles except altruism and virtue ethics, which were equally prevalent in the narrative responses of first-year and senior students. Coded data pertaining to alcohol use was less consistent, with seniors' narrative responses showing more evidence of altruism than first-year students.

Repeated measures ANOVA also found that first-year students applied principles of virtue ethics more than senior students did across all ethical scenarios. This result was not corroborated by participants' coded narrative responses, where little difference was observed in the degree to which students' decision making reflected consideration of virtue ethics. The significance of this finding is it suggests first-year student's subjective sense of their adherence to the principles of virtue ethics did not match the objective assessment of the rationale articulated for their ethical decisions. 


\section{Triangulation of Institutional Values Data}

In reviewing the consolidated data in Table 2, certain values were observed to consistently rank higher or lower across all scenarios than others, and certain scenarios elicited greater agreement in rankings across all values than others. As with the ethical principles, it is clear the application of institutional values depends on the situation and context. Two institutional values, Cura Personalis and Magis, were least evident in students' ethical decision-making across all scenarios, while both solidarity and kinship, and service rooted in justice and love, were applied consistently to all ethical situations presented. Closer analysis of discrepancies between the qualitative and quantitative results of this study, revealed the greatest disparity occurred in the rankings for discernment. Coded narrative responses ranked higher than survey data for all scenarios except time management, with the largest discrepancies observed for cheating on an exam, use of club funding, and underage alcohol use. This discrepancy was observed for both first-year and senior students, indicating both student populations evidenced more discernment in their narrative responses than in their subjective assessment of the consideration given to how their actions would "promote a sense of universal well-being or balance in the world".

Reviewing discrepancies specific to certain scenarios, both first-year and senior students reported applying service rooted in justice and love more than was observed in their narrative responses to the under-aged alcohol use scenario. This same discrepancy was also observed, for first-year students only, with respect to the time management, use of club funding, and cheating on an exam scenarios. First-year students also reported considering solidarity and kinship more than seniors in responding to the underaged alcohol use scenario. Finally, these rankings were reviewed in comparison to statistical differences observed through the repeated measures ANOVAs to determine if the results are corroborated by the qualitative data. Repeated measures ANOVAs indicated a significant difference between first-year and senior students with respect to institutional values considered in response to the cheating on an exam and underage alcohol scenarios. Coded narrative data corroborated this finding only with respect to the application of reflection in responding to the underage alcohol scenario; other coded responses to these scenarios were roughly equal between the two groups, except where seniors showed more consideration of discernment in the context of underage alcohol, and reflection in the context of cheating on an exam.

Repeated measures ANOVA also found that first-year students applied the institutional value Cura Personalis, more than senior students did across all ethical scenarios. This result was not corroborated by participants' coded narrative responses, where little difference was observed in the degree to which students' decision making reflected consideration of Cura Personalis. The significance of this finding is it suggests first-year student's subjective sense of their concern for caring for the whole person was greater than the objective assessment of the rationale articulated for their ethical decisions.

\section{CONCLUSIONS}

This mixed-methods case study produced an extensive body of both qualitative and quantitative data to inform the research questions comparing ethical decision-making among first-year and senior undergraduate students.

\section{Addressing Research Questions}

These data provide convincing evidence that ethical decision-making among both first-year and senior students is situational (RQ1). All within-subjects analyses related to the application of ethical principles were significant. This demonstrates students adjust the ethical principles they employ in making ethical decisions to match the particular circumstances of the situation: Kant's categorical imperative was the favored principle for making decisions about underage alcohol use. Pragmatism was the principle preferred for addressing cheating on an exam, while the principle of altruism was employed to confront issues of time management. The inappropriate use of social media was dealt with through a combination of categorical imperative and altruism, and the misuse of club funding through a combination of categorical imperative and utilitarian principles. 
Results of this case study found extensive evidence that institutional values are reflected in students' ethical decision-making, and showed some variation across different ethical situations (RQ2). All withinsubjects analyses related to the application of institutional values were significant. While some values were more evident in students' ethical decision-making than others, students' ethical decisions generally reflected multiple institutional values simultaneously. The most frequently employed institutional values across all ethical scenarios were solidarity and kinship, and service rooted in justice and love. Discernment and reflection were employed to a lesser extent across all scenarios, while Cura Personalis and Magis were applied more selectively, in the context of time management and under-aged alcohol use, respectively.

This case study produced evidence that incoming first-year students differ from graduating seniors with respect to their application of both ethical principles and institutional values (RQ3). This evidence materialized in the context of some, but not all, ethical scenarios. Four between-subjects tests yielded significant results. Statistically significant differences were found between these student groups in 2 of 5 scenarios, with respect to the application of ethical principles (time management and under-aged alcohol use), and institutional values (cheating on an exam and under-aged use of alcohol). Students' consideration of the ethical dilemma posed by under-aged use of alcohol is the only scenario that produced significant differences between first-year and senior students with respect to the application of both ethical principles and institutional values.

The question of whether first-year and senior students who employ the same ethical principles in their decision-making integrate institutional values to differing degrees (RQ4) was most directly addressed in this study by the interaction effects reported as part of the repeated measures ANOVA assessment of survey data. None of these interaction effects gained significance. There was no evidence the students who applied the same ethical principle to resolve a particular ethical dilemma differed with respect to the values expressed as part of the reason for their actions.

\section{Implications for Theory \& Practice}

This study introduces a new dimension to the study of ethical development of undergraduate students by focusing on the content of their ethical decisions. Participants in this study demonstrated fluidity in selectively applying ethical principles to a range of ethical scenarios. The finding that both incoming firstyear students and seniors vary the ethical principles they employ to fit different situational circumstances they confront advances theoretical knowledge of ethical decision-making by offering a counter narrative to the assumption that individuals tend to adopt one preferred ethical principle and apply it to every ethical decision (Chikeleze \& Baehrend, 2017).

There was also variability in how students employed institutional values in the context of ethical decision-making, but that pattern of variability was more consistent across scenarios. That is, students applied the same values more than others across most ethical dilemmas. The values of service, solidarity, kinship and discernment were applied in almost every circumstance, while other values such as reflection, caring for the whole person, and doing more than required, tended to be less frequently employed. These results have the potential to enhance our theories of ethical decision-making by inviting research exploring the relationship between values and ethical decision-making, and whether some values are more integral to resolving complex ethical dilemmas. The fact that no interaction effects were found between ethical principles and institutional values, makes it more likely such systematic relationships do exist that are not moderated by circumstances.

The differences in ethical decision-making between first-year and senior students documented in this study were robust in relation to certain ethical contexts, and related to both ethical principles and institutional values. The under-aged use of alcohol scenario elicited differences between first-year and senior students in the application of both ethical principles and institutional values, while cheating on an exam evoked differences only with respect to institutional values, and time management only revealed differences in ethical principles. Perhaps the most surprising aspect of these results was that first-year students, rather than seniors, evidenced greater consideration of both ethical principles and institutional values in relation to each of these between-subjects effects. The theoretical and practical implications of this finding are unclear, but invite speculation about whether experience and exposure to particular ethical 
dilemmas renders the cognitive dimensions of ethical decision-making less accessible to conscious awareness, as these responses become more routinized.

With respect to higher education administrators in general, and student affairs professionals in particular, results of this study provide no direct evidence undergraduate students experience systematic changes in their ethical decision-making while enrolled in college. More importantly, however, the evidence of discrepancies between subjective and objective assessments of the content of student's ethical decision-making among both first-year and senior students, suggest opportunities exist for raising students' self-awareness of their ethical decision-making processes, with respect to both the principles and values reflected. The fact that students at all levels demonstrate situational fluidity in the application of ethical principles should encourage educators to provide enhanced opportunities for students to gain greater insight into their own ethical decision-making processes and the consequences of choosing alternative courses of action.

\section{Limitations and Future Research}

The results of this study invite future research both to address limitations of design and to build on the findings reported.

\section{Research to Address Limitations}

The use of case study methodology in this research permitted an in depth analysis of student ethical decision-making in the context of specific institutional values. The mixed methods design, enabling triangulation of study results, yielded dimensionality that would have otherwise been overlooked. Of particular note is the finding that despite evidencing little consideration of the principles of virtue ethics in their narrative responses, both first-year and senior students reported choosing "actions that promote moral goodness for all." However, these methodological choices also introduce limitations that should be acknowledged and addressed through future research.

The first methodological limitation concerns the degree to which findings of this study can be extrapolated to other academic institutions. To the extent the population of students attending the case study institution are representative of the broader population of college-attending students, these results may prove to be normative. Replicating this study at other universities, using the scenarios in Appendix A and survey questions in Appendix B, would increase confidence in the extrapolation of findings to other academic institutions. These studies could include additional case studies, or multi-institutional samples, where variations in institutional values could serve as a control variable. Determining whether the results obtained in this study extrapolate to academic institutions that have different institutional values, is as important as establishing whether results can be replicated at other Jesuit universities. This line of research might include a study comparing public and religiously-affiliated institutions.

The cross-sectional nature of this study also limits the extent to which differences between first-year and senior students can be attributed to development or institutional influence. Longitudinal studies tracking changes in the ethical decision-making of matriculated students over the entirety of their undergraduate tenure are needed to confirm these findings. Following the same participants over their four-year undergraduate tenure would permit researchers to observe the maturation, growth, and development of students' ethical decision-making over time. It could also provide an opportunity to assess the impact of various co-curricular experiences and academic courses on students' ethical development. Such studies would further illuminate the contribution of higher education to students' ethical decision-making.

\section{Research to Extend Results}

The fact that only some of the ethical scenarios in this study evidenced significant differences between incoming first-year student and graduating seniors, in the application of both ethical principles and institutional values, is a finding that invites further empirical inquiry. Given the significant amount of within-subjects variability across multiple ethical scenarios, the small sample size in this case study may have been insufficient to detect more modest between-subject effects. Follow-up studies with larger samples, honing in on decision-making related to specific contextual component, are needed to fully 
understand the extent to which first-year and senior students differ with respect to ethical decisionmaking.

Other opportunities for future research include narrative and phenomenological studies designed to explore and seek explanations for the rationales underlying ethical decision making among these two undergraduate populations. As we continue research to further illuminate the pattern of differences observed in this study, studies designed to assess the experiential dimensions of ethical decision making can provide insight into why and how students arrive at the ethical decisions that inform their actions in different social situations. Extending the study of ethical decision making along these lines could shed light on some of the counterintuitive findings from this study, including why first-year students report having a subjective sense that they consider ethical principles and institutional values to a greater degree than seniors. Exploring whether this difference due to the cognitive processes involved in reaching ethical decisions in unfamiliar contexts, or reflects the halo effect of first-year students subconsciously seeking to look good in the eyes of the researcher, could also be assess using laboratory techniques involving traditional experimental design. Both types of studies would extend the line of research begun with this study and contribute to a robust research agenda

Building this research agenda must include studies designed to assess potential factors that mediate or moderate the development of ethical decision-making among undergraduate students. In addition to documenting difference, these studies would begin to document the experiences that affect development of ethical reasoning in the academic environment. Previous studies of college student development point to the importance of including both co-curricular programming and extracurricular experiences as contributing factors to this development. Studies designed to capture the experiential wisdom of seasoned student affairs professionals responsible for designing such programming could represent a valuable first step toward identifying the most promising factors to assess.

One of the most challenging questions posed by results of the current study that invites further research is differentiating the effect of prior experience from the influence of developmental experiences and institutional values on the ethical development of undergraduate students. In the design of this case study, some effort was made to control for prior experience by excluding from the sample of incoming first-year students those who had attended high schools with similar institutional missions. But one of the factors not considered was the extent to which some of the values reflected in institutional mission of the case study university are more pervasive in American culture generally (solidarity and kinship, service), while others were more unique to the academic institution studied (Cura Personalis, Magis). The remaining values may be common to higher education institutions in general (reflection, discernment). The fact that these groups of values were differentially reflected in the decision-making rationales of participants in this study, suggests future studies should attempt to control for the cultural uniqueness of institutional values, in order to better differentiate the influence of institutional mission from any carryover effect that may be reflected in the study of undergraduates' ethical decision-making.

Finally, we cannot conclude from the results of this study anything about the causes underlying students' application of ethical principles and Jesuit values, only that the differing patterns among these populations are not that great, and there do not appear to be dramatic changes during the college experience. Similarly, no data were collected to inform whether students do deepen their ethical decision making during the years they are enrolled as undergraduates, but not due to any direct influence of the academic environment. Additional ways to expand this study that might shed some light on these questions would be to study the comparative influence of major or college (e.g. school of business, arts and sciences, etc.) on undergraduate students' ethical decision-making. Previous research shows that while most colleges and universities have ethics as part of their educational mission, schools of business are most likely to require students to take ethics courses (Craft, 2013; King \& Mayhew, 2002). Documenting the effects of formal study of ethics as part of the undergraduate curriculum could be an important extension to our knowledge of the impact of undergraduate education on ethical decisionmaking. 


\section{REFERENCES}

Alghalith, N. (2018). Using course-embedded assessment: Defining and assessing ethical reasoning skills of MIS students. Journal of Higher Education Theory \& Practice, 18(5), 51-55.

Almasri, N., \& Tahat, L. (2019). Business students' ethics in the digital age. Journal of Higher Education Theory \& Practice, 18(7) 24-33.

Anderson, E. (2014). Dewey's Moral Philosophy. In The Stanford Encyclopedia of Philosophy. Stanford, CA: Center for the Study of Language and Information, Stanford University.

Astin, A. W. (1984). Student involvement: A developmental theory for higher education. Journal of College Student Development, 25, 297-308.

Byron, W. J. (1998, October 31). Ten building blocks of Catholic social teaching. America: The Jesuit Review. Retrieved from https://www.americamagazine.org/faith/1998/10/31/ten-building-blockscatholic-social-teaching

Chikeleze, M., \& Baehrend, W. R. (2017). Ethical leadership style and its impact on decision-making. Journal of Leadership Studies, 11, 45-47.

Craft, J. L. (2013). A review of the empirical ethical decision-making literature: 2004-2011. Journal of Business Ethics, 117, 221-259.

DeGeorge, R. T. (2010). Business ethics (7th ed.). Upper Saddle River, NJ: Prentice Hall.

Dion, M. (2012). Are ethical theories relevant for ethical leadership? Leadership \& Organization Development Journal, 33, 4-24.

Fesmire, S. (2013). John Dewey and moral imagination: Pragmatism in ethics. Bloomington, IN: Indiana University Press.

Graham, G. (2004). Eight theories of ethics. New York: Routledge.

Heyler, S. G., Achilles, A. A., Walker, A. G., \& Collier, D. Y. (2016). A qualitative study investigating the ethical decision making process: A proposed model. The Leadership Quarterly, 27, 788-801.

Johnson, C. E. (2018). Meeting the ethical challenges of leadership (6th ed). Thousand Oaks, CA: Sage.

Jones, C. E., \& Watt, J. D. (1999). Psychosocial development and moral orientation among traditionalaged college students. Journal of College Student Development, 40, 125-131.

King, P. M. \& Mayhew, M. J. (2002). Moral judgement development in higher education: Insights from the Defining Issues Test. Journal of Moral Education, 31, 247-270.

Kraut, R. (2016). Altruism. In The Stanford Encyclopedia of Philosophy. Stanford, CA: Center for the Study of Language and Information, Stanford University.

Mayhew, M. J., \& King, P. (2008). How curricular content and pedagogical strategies affect moral reasoning development in college students. Journal of Moral Education, 37, 17-40.

Mayhew, M. J., Seifert, T. A., \& Pascarella, E.T. (2012). How the first year of college influences moral reasoning development for students in moral consolidation and moral transition. Journal of College Student Development, 53, 19-40.

Morales-Sánchez, R., \& Cabello-Medina, C. (2103). The role of four universal moral competencies in ethical decision-making. Journal of Business Ethics, 116, 717-734.

Oliver, D. E., \& Hioco, B. (2012). An ethical decision-making framework for community college administrators. Community College Review, 40, 240-254.

Rawls, J. (2001). Justice as fairness: A restatement. E. Kelly (Ed.). Cambridge, MA: The Belknap Press of Harvard University Press.

Rosen, B. (1978). Strategies of ethics. Boston, MA: Houghton Mifflin.

Salimi, A. Y., Kornelus, A., \& Abo-Hebeish, A. (2016). Improvement in accounting students' perception and judgement on ethical issues. Journal of Higher Education Theory \& Practice, 16(3), 51-56.

Statistics Solutions. (2018). Conduct and interpret a repeated measures ANOVA.

Stringer, J., \& Swezey, E. (2006). The purpose of a student affairs preparation program within Jesuit higher education. Catholic Education: A Journal of Inquiry and Practice, 10, 181-198.

Whitley, B. E., \& Kite, M. E. (2013). Principles of research in behavioral science (3rd edition). New York: Routledge.

Wilson, K. L., Rest, J. R., Boldizar, J. P., \& Deemer, D. K. (1992). Moral judgment development: The effects of education and occupation. Social Justice Research, 5, 31-48. 


\section{APPENDIX A}

\section{Ethical Scenarios}

The following five hypothetical scenarios formed the basis for eliciting the qualitative data analyzed in this study. Each scenario poses a different ethical dilemma in contexts undergraduate students might encounter during their academic tenure at any institution of higher education.

\section{Cheating on an Exam}

The semester has been hard for you academically and you have a big test coming up in one of your classes. You happen to be in this class with several acquaintances a couple of days before the test and suggest forming a study group to review. You spend some time studying together the weekend before the test, but your classmates don't seem too interested and decide to go out with friends instead of staying in to continue studying.

You know that you have to do well on this test to do well in the class, so you continue to study, and the day of the test feel fairly confident in your preparation. Additionally, your professor announces the test will be graded on a curve, so you feel good about how you will do. Part way through the test, your professor steps out of the room and you notice that two of the people you tried to study with are using their phones to look up answers. One of them even sees that you notice and winks at you, as if you're in on the cheating.

\section{Use of Club Funding}

You are a member of a large student organization that receives money from the Student Government Association to put on events. This year, however, your club has come up with a new idea for an event and needs additional funding to make it happen. You volunteer to help the treasurer of the organization put together a budget proposal to present to the club funding board to request additional money. Your funding request is approved and your organization begins to plan the event.

During event planning, the president of the organization decides to use some of the new funds for a different program, one that not everyone agrees the club should fund. You know that the money was approved for a specific event but the president insists that it's ok to use the money for this other program.

\section{"Fake" Social Media Accounts}

One day you are scrolling through Instagram and see that the site has "suggested" that you become friends with what appears to be a funny account from someone at the school. It appears as though this account is a "fake Instagram" account or "Finsta" account, and you think you know who runs it, someone you know from class who is a well-known student leader. You decide to follow the account because it seems funny.

A few weeks later while scrolling through Instagram, you notice that this account has posted a meme using a photo of someone else on campus, making fun of them for what they are wearing. Even though the account is 'fake', the derogatory comments are real, raising questions about whether context matters in determining what constitutes online harassment.

\section{Time Management}

You are the vice president of a well-known student organization on campus. The President, someone you respect and look up to, seems to have it all together. That person is a great student, does good work for the organization, and is in the process of applying to grad schools and internships. Recently, however, you have noticed that the President hasn't been following through on all responsibilities of the position, leaving you to pick-up the slack. You approach the President to ask about this, and are told that classes are busy, making it hard to get things done for the organization. Later, you hear this individual give a similar excuse to a professor about a late assignment, blaming their tardiness on your organization. Your group has a major event coming up and you know the success of that event depends upon the President 
doing some of the work. You are concerned whether or not this individual can be counted on to pull their weight.

\section{Underage Alcohol Use}

One weekend, you are at a party, and the alcohol is freely flowing. You and your friends are underage, but that doesn't seem to bother anyone. One of your friends ends up getting really drunk, so the rest of you decide you need to leave and return to your residence hall room. On the way back to campus, your friends seems to be increasingly non-responsive. You think that you should call Campus Police for medical help but the rest of your friends know that this friend has already had one alcohol violation this year and are worried that they might be in a lot of trouble if they get another. They insist that your friend can "sleep it off" and are sure they will be fine. Besides, nobody else wants to get in trouble either and you've all be drinking that night. 


\section{APPENDIX B}

\section{Likert Survey Questions}

1

Not considered

in response
2

Considered but not a

major factor in response
3

Considered but greater weight given to other factors
4

Considered a major

factor in response

1. To what degree did you consider the greatest good for the greatest number of people in your responses to the hypothetical scenarios?

2. To what degree did you consider the need to do what was right no matter the cost to yourself or others in your responses to the hypothetical scenarios?

3. In your responses, to what degree did you attempt to guarantee equal rights/opportunities for all parties involved in the hypothetical scenarios?

4. To what degree did you mentally test out various courses of action, considering possible outcomes and how others might respond, or how you have solved similar problems in the past when responding to the hypothetical scenarios?

5. To what degree did you choose actions that put the needs of others ahead of your own selfinterests in responding to the hypothetical scenarios?

6. To what degree did you choose actions that promote moral goodness for all in your responses?

7. To what degree did you consider the need pause and take time to contemplate solutions before taking action in responding to the hypothetical scenarios?

8. To what degree did you consider how the actions outlined in your responses to the hypothetical scenarios would promote a sense of universal well-being or balance in the world?

9. To what degree did your responses reflect identification with the other individuals in the hypothetical scenarios, or putting yourself in their shoes?

10. To what degree did your responses aim to right the wrongs and promote good will for the individuals in the hypothetical scenarios?

11. To what degree did you consider the unique individuality and holistic needs (mind, body, spirit) of the individuals involved in the hypothetical situations in your responses?

12. To what degree did your responses reflect consideration for how you might go beyond expectations, or do more than required, to address the needs of individuals in the hypothetical scenarios? 